\title{
Effect of Jaw Movement in Blink Rate and Tear Volume
}

\section{Premnath Krishnasamy ${ }^{1}$, Hari ${ }^{1 *}{ }^{*}$, Sumanth Kumar H $^{2}$ and Pooja Anemath $^{2}$}

${ }^{1}$ Assistant Professor, Vittala International Institute of Ophthalmology,

Hosakerehalli, Banashankari Bangalore, India

${ }^{2}$ Vittala International Institute of Ophthalmology, Hosakerehalli, Banashankari

Bangalore, India

*Corresponding Author: Hari R, Assistant Professor, Vittala International Institute of Ophthalmology, Hosakerehalli, Banashankari Bangalore, India.
Received: December 07, 2021

Published: January 31, 2022

(C) All rights are reserved by Hari R., et al.

\section{Abstract}

Aim: To find the effect of blink rate and tear volume during jaw movement

Methodology: There are 50 subjects which were included in the study that are based on inclusion and exclusion criteria. First, we recorded Non-invasive breakup time, tear meniscus height, and Schirmer's test, that are followed by blink rate and inter blink interval which was recorded in video. Lastly, the parameters were taken without jaw movement and during jaw movement hence the results were compared.

Results: The report results were compared based on normal, reflex, and basal secretion with and without jaw movement and all of them are correlated.

There was a significant reduction in blink rate during jaw movement in all three conditions with which show $24.1 \pm 10.33,31.72$ $\pm 13.9,24.0 \pm 12.97$ respectively in without jaw movement to $17.5 \pm 8.34,25.72 \pm 13.28,18.46 \pm 11.12$ respectively during jaw movement.

There was a notable increase in inter blink interval values during jaw movement in all three conditions from $3.02 \pm 1.33 \mathrm{sec}, 2.3 \pm$ $1.21 \mathrm{sec}, 3.59 \pm 2.93 \mathrm{sec}$ respectively in without jaw movement to $4.32 \pm 2.52 \mathrm{sec}, 3.04 \pm 1.68 \mathrm{sec}, 3.59 \pm 2.93 \mathrm{sec}$ respectively during jaw movement.

There was a slight reduction in non-invasive tear break up time during jaw movement in all three conditions which appear to be $7.97 \pm 1.38 \mathrm{sec}, 6.76 \pm 1.12 \mathrm{sec}, 7.23 \pm 1.31 \mathrm{sec}$ respectively in without jaw movement and $6.06 \pm 0.89 \mathrm{sec}, 4.5 \pm 1.23 \mathrm{sec}, 5.84 \pm 1.34$ sec respectively during jaw movement.

There was pointless reduction in tear meniscus height during jaw movement in all three conditions with $0.34 \pm 0.06 \mathrm{~mm}, 0.37 \pm$ $0.08 \mathrm{~mm}, 0.35 \pm 0.07 \mathrm{~mm}$ respectively in without jaw movement to $0.33 \pm 0.06 \mathrm{~mm}, 0.35 \pm 0.08 \mathrm{~mm}, 0.34 \pm 0.08 \mathrm{~mm}$ respectively in during jaw movement.

Conclusion: From above data, we can conclude that there was remarkable reduction in blink rate, tear stability, tear secretion during jaw movement where as slightly increased inter-blink interval. Likewise, there were no change in TMH during jaw movement. Keywords: Schirmer Strips; Non-invasive Tear Break Up Time; Tear Meniscus Height; Proparacaine 0.5\%; Mastication 


\section{Abbreviations}

WOJM: Without Jaw Movement; WJM: With Jaw Movement; BR: Blink Rate; TMH: Tear Meniscus Height; NITBUT: Non Invasive Tear Break Uptime; SCH 1: Schirmer 1; SCH 2: Schirmer 2

\section{Introduction}

The normal blinking is essential to make sure the normal distribution of the tear film and to protect the ocular surface.

Thus, it has been reported that the normal spontaneous blink rate is between $12 / \mathrm{min}$ to $15 / \mathrm{min}$.

As blinking is the rapid closure and opening of the eye, it is an essential function of the eye that helps in spreading tears across and removes the debris from the surface of the cornea and conjunctiva. The blink rate can be damaged by factors like medication, fatigue, eye injury, and any diseases. The main muscles, in the upper eyelid, which control the opening and closing are the orbicularis oculi and levator palpebrae superioris muscle.

Types of blinking

- $\quad$ Spontaneous blinking

- $\quad$ Reflex blinking

Mouth and jaw movements

The functions of the trigeminal (cranial nerve $\mathrm{V}$ ) and facial (cranial nerve VII) nerves that help in eyelid interaction. Although, damage to the trigeminal system leads mainly to a loss of sensation in the face but the mandibular division of the trigeminal nerve controls jaw movement. As it is observed damage to the facial nerve mainly causes the weakness of the muscles of facial expression and it may also affect taste sensation in the anterior part of the tongue.

The temporalis, masseter, and pterygoid muscles (muscles of mastication) are supplied by the motor division of the mandibular branch of cranial nerve $\mathrm{V}$ and that help in mouth as well as jaw movements. Likewise, supranuclear innervation of these muscles (hemispheric and brainstem pyramidal and extrapyramidal systems) is essentially symmetrical bilaterally.

\section{Effect of neurological factors on blinking}

The normal blinking is important for the normal distribution of the tear film and to protect the ocular surface. The blinking abnormalities that may result in poor distribution which can cause damage to the ocular surface.
The blink rate may be affected by many factors such as Parkinson's disease and corneal sensitivity disorders which reduces the blink rate of an individual and causes more exposure to the ocular surface. In this condition, there will be a pause in the opening and closing of the eyelid and they are unable to blink.

\section{Review of Literature}

Michael J Doughty 2017 [1] Dec 12.: conducted a study Influence of mouth and jaw movements on dynamics of spontaneous eyeblink activity assessed during slit-lamp biomicroscopy. Repeat video recordings of five minutes duration were made on 76 young adult emmetropic subjects aged 18-25 years. The subjects were instructed to direct their gaze horizontally toward a distant target with the entire cornea of the left eye illuminated with a broad beam of cobalt blue light. Repeat recordings were made:

- $\quad$ On the following day in silence in group one;

- Immediately in silence for group two; and

- Immediately either while holding their mouth open slightly or while responding to casual conversation for groups three and four.

They found a For group one the averaged SEBR values for the first and second recordings were 13.5 and 14.6 blinks/minute, and similar results were obtained for group two if the subjects were relaxed (for example 13.9 and 12.0 blinks/minute). A slight, but statistically significant, the time-related decline in SEBR was usually noted. For non-relaxed (restless) subjects exhibiting spontaneous mouth and jaw movements while being video graphed, the averaged SEBR values were around 27 blinks/minute. For groups three and four, analyses of those individuals who managed to maintain a mouth open posture for the video recordings, the average SEBR was 7.2 blinks/minute, while those engaged in casual conversation had an average SEBR of 20.3 blinks/minute. They concluded that there were Mouth and jaw movements and a non-relaxed state can substantially affect spontaneous eye blinking.

Mareike Brych1, Supriya Murali1, Barbara Händel1 Department of Psychology III, the University of Würzburg on July 31, 2020: conducted a study on the motor aspect of speaking influences the blink rate. 30 psychology students of the University of Würzburg (mean age: 20.17 years $\pm 1.8666 \mathrm{SD}, 2$ male) took part in the study.

To test for cognitive influences on the blink rate, we compared baseline (no task) with 104 "normal talking" and with "talking in- 
side the head". A repeated measures 2-factor ANOVA 105 compared the blink rate between these conditions as well as between the five repetitions of 106 each condition within subjects. A significant main effect of conditions was revealed $(F(1.31,32.86)=25.22, p$ $<.001$, np $2107=0.50$, Greenhouse-Geisser corrected (GG)). Posthoc pairwise $\mathrm{t} 108$ tests revealed a significant difference between normal talking and talking inside the head $(\mathrm{p}<109.001)$ as well as between baseline and normal talking $(p<.001)$. There was neither a significant 110 main effect of repetition nor a significant interaction effect (both $\mathrm{F}<1$ ) They concluded that there was motor activity during speaking has a major influence on 231 blinkings, while auditory input and cognitive processes only have a minor effect. Motor Activity Influences the Blink Rate 13232 results, we advise caution when using blinks as neurological indicators during patient 233 interviews without closely monitoring the time of talking.

Felipe Placeres Borges Denny Marcos Garcia, Antonio Augusto Velasco E Cruz Jul-Aug 2010 [4]: conducted a study on the Distribution of spontaneous inter-blink interval in repeated measurements with and without topical ocular anesthesia. Inter-blink time was measured in 15 normal subjects ranging from 19 to 32 years (mean $\pm \mathrm{SD}=23.9 \pm 3.20$ ) with the magnetic search coil technique on 3 different occasions, the last one with topical ocular anesthesia. One-way analysis of variance for repeated measurements showed that topical anesthesia significantly reduced the blink rate (blinks per minute), which was constant in the first two measurements ( $\mathrm{F}$ $=8.27, \mathrm{p}=0.0015$. First measurement: mean $\pm \mathrm{SD}=13.7 \pm 7.8$; second measurement: $13.1 \pm 8.5 \mathrm{SD}$; with topical anesthesia: $=7.2 \pm$ 4.6). However, distributions shape was not affected when the blink rate was reduced. The three distributions followed a Log-Normal pattern, which means that the time interval between blinks was symmetrical when the time logarithm was considered.

They concluded that Topical ocular anesthesia reduces the rate of spontaneous blinking, but does not change the distribution of inter-blink time intervals.

Michael J. Doughty November 2001 [2]: conducted a study on the Consideration of Three Types of Spontaneous Eyeblink Activity in Normal Humans: during Reading and Video Display Terminal Use, in Primary Gaze, and while in Conversation. These were compared with assessments of SEBR in young adult subjects under equivalent conditions.
Assessments of spontaneous eyeblink activity revealed that SEBR in a reading posture is lower than that in primary gaze, and SEBR is higher when subjects are in conversation. Such differences are also generally found in literature reports, especially if the primary gaze assessment is carried in silence.

Electrophysiological measures of SEBR yield slightly higher values compared with observational techniques. Statistical analysis (with the calculation of $95 \%$ confidence interval values) indicates that reading-SEBR should be between 1.4 and 14.4 eyeblinks/min, primary gaze-SEBR between 8.0 and 21.0 eyeblinks/min, and conversational-SEBR between 10.5 and 32.5 eyeblinks/min for normal adults.

They concluded that It is inappropriate to simply state a value for spontaneous eyeblink rate because it is so dependent on experimental conditions. It is further proposed that reports of SEBR measures should be prefixed by these experimental conditions, namely reading-SEBR, primary gaze-SEBR (in silence), and conversationalSEBR.

\section{Need of the study}

To understand the co-relation of blink rate and tear volume without jaw movement and during jaw movement in primary gaze position.

\section{Aims and Objective}

Aim

To find the effect of blink rate and tear volume during jaw movement.

\section{Objective}

To monitor and compare the blink rate and inter blink interval at the constant fixation of the target in normal, reflex, and basal secretion with and without jaw movement.

\section{Methodology}

- Study population: 50 healthy subjects [age between 20 -30 years]

- Study design: Prospective experimental study

- Study area: Vittala international institute of Opthalmology

- Study duration: 6 months

- Data collection: Technique based on inclusion and exclusion criteria subjects enrolled in this study. 
Inclusion criteria

- Healthy subjects were recruited for the study [20-30 years age]

- $\quad$ Refractive error [less than $+/-4.75]$.

Exclusion criteria

- Any ocular allergy,

- Contact lens wear,

- Any systemic disease,

- Oral medication,

- $\quad$ High myopes [>-4.75]

- Neurological diseases

- Ptosis

- Trauma

- Facial asymmetry,

- $\quad$ Dry eye.

Material required

- $\quad$ Distance and near vision chart[Logmar]

- $\quad$ Retinoscope [Heine beta 200 STREAK RET.2.5V]

- $\quad$ Slit lamp [Haag streit biomicroscope]

- Keratometer [Bausch and lomb]

- Direct ophthalmoscope

- $\quad$ Schirmer's strip [Whatman's filter, width, and length- 5X35]

- $\quad$ Canon camera 1300D

- Tripod

- Chewing gum [Happydent white sugar-free]

- Stopwatch

- Antibiotic drops [Ciprofloxacin HCL $0.5 \mathrm{mg}$ equivalent to $3 \mathrm{mg}$ base, $0.3 \%$ ]

- $\quad$ Topical anaesthesia [Proparacaine $0.5 \%$ hydrochloride $5 \mathrm{mg}$ ].

Procedure

Flow chart

\section{Study parameter}

The study was conducted on the premises of Vittala international institute of ophthalmology Bengaluru in subjects of Bsc students with the support of staffs. After explaining the procedure clearly,

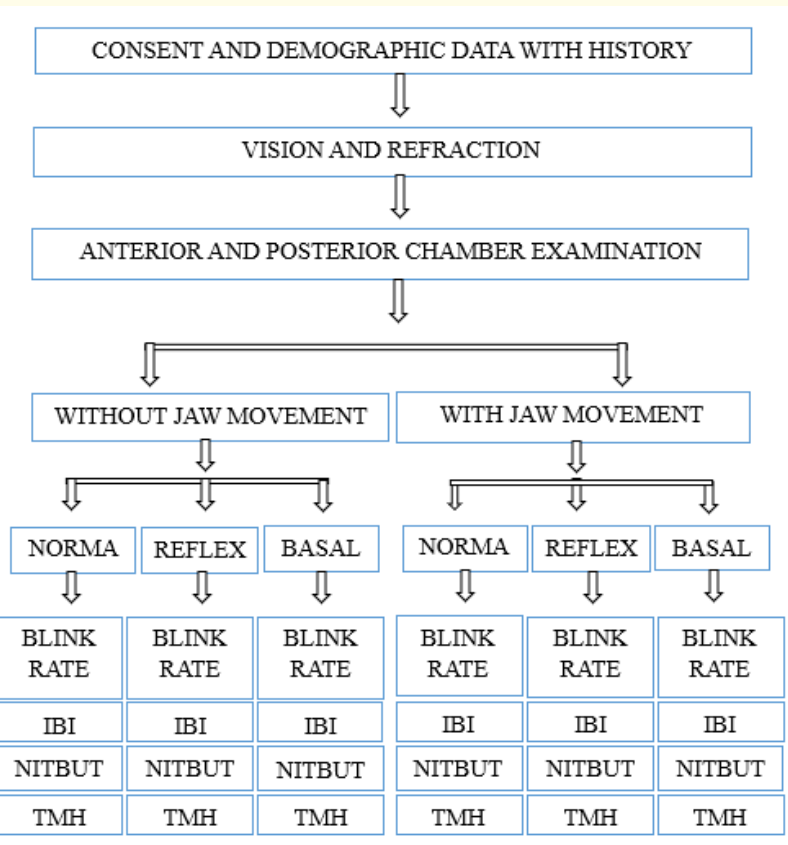

Flow Chart

consent was taken from the subjects, after which demographic data was collected. The subjects were assessed for any pathology using slit-lamp as well as fundus was also examined through direct ophthalmoscope. After fundus examination, minimal of two hours gap was given to patient. Then visual acuity was performed using log mar visual acuity chart. Objective, as well as subjective retinoscopy, was performed. On the basis of inclusion criteria the subjects were taken for this study.

Normal room illumination with silent environment maintained and functionally and the pathologically better eye is chosen for the test. The patient is instructed to look at the LCD monitor for Letter E of $1.0[4 \mathrm{M}]$ and to observe orientation throughout the examination without any response.

Blink rate is monitored and recorded in-camera for $1 \mathrm{~min}$ and the procedure followed was to simply replay on the recording and manually count the number of blinks in each successive minute, replaying sections of the recording if there was any uncertainty after recording NITBUT and TMH was observed with keratometer and slit-lamp respectively. 
The same was recorded in

- Normal condition with and without jaw movement

- Reflex secretion with and without jaw movement

- Basal secretion with and without jaw movement [The time interval between each stage is $15 \mathrm{~min}$ ]

Statistical analysis

- The data were analyzed using one way ANOVA Test [Statistical package of social science] Version 20.0

- $\quad$ Paired sample t was used for the result.

Analysis

Formula used:

$N=\frac{2\left(Z_{1-\frac{\alpha}{2 * k}}+Z_{1-\beta}\right)^{2} \sigma^{2}}{d^{2}}$

$\sigma 1$ - standard deviation of group 1

$\sigma 2$ - standard deviation of group 2

$\sigma$ - average standard deviation $\mathrm{d}$ - the minimum difference in the values which will make a clinically relevant impact.

\section{Results}

A total of 50 eyes of 50 subjects were investigated for the effect of blink rate and tear volume during jaw movement, study group was 2030 years, There were 30 females and 20 males.

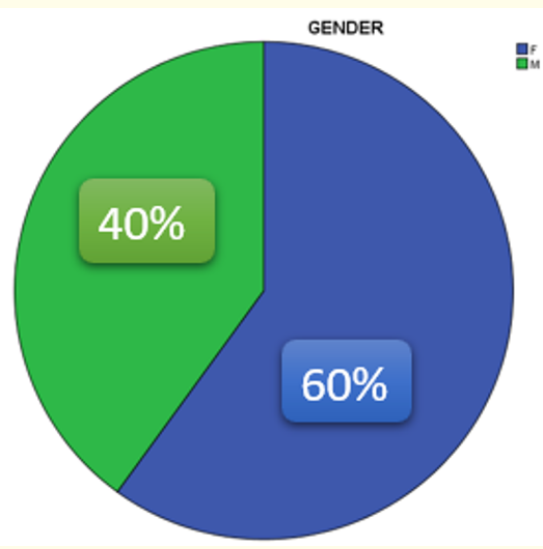

Graph a: Gender distribution Graph.

\begin{tabular}{|c|c|c|c|c|c|c|c|c|c|c|c|c|c|c|c|}
\hline & \multicolumn{5}{|c|}{ Normal } & \multicolumn{5}{|c|}{ Reflex } & \multicolumn{5}{|c|}{ Basal } \\
\hline & WOJM & DJM & MD & $\mathbf{t}$ & $\mathbf{P}$ & WOJM & DJM & MD & $\mathbf{t}$ & $\mathbf{P}$ & WOJM & DJM & MD & $\mathbf{t}$ & $\mathbf{P}$ \\
\hline $\mathrm{BR}$ & $\begin{array}{l}24.1 \pm \\
10.33\end{array}$ & $\begin{array}{l}17 . \pm \\
8.34\end{array}$ & $\begin{array}{l}6.6 \pm \\
8.52\end{array}$ & 5.55 & $<0.001$ & $\begin{array}{c}31.72 \pm \\
13.9\end{array}$ & $\begin{array}{c}25.72 \pm \\
13.28\end{array}$ & $\begin{array}{c}6 \pm 11 \\
05\end{array}$ & 3.84 & $<0.001$ & $\begin{array}{l}24.0 \pm \\
12.97\end{array}$ & $\begin{array}{c}18.46 \pm \\
11.12\end{array}$ & $\begin{array}{c}5.6 \pm \\
10.14\end{array}$ & 3.91 & $<0.001$ \\
\hline IBI & $\begin{array}{c}3.02 \pm \\
1.33\end{array}$ & $\begin{array}{c}4.32 \pm \\
2.52\end{array}$ & $\begin{array}{c}-1.3 \pm \\
2.17\end{array}$ & -4.24 & $<0.001$ & $\begin{array}{l}2.3 \pm \\
1.21\end{array}$ & $\begin{array}{c}3.04 \pm \\
1.68\end{array}$ & $\begin{array}{c}-0.74 \pm \\
1.35\end{array}$ & -3.85 & $<0.001$ & $\begin{array}{c}3.59 \pm \\
2.93\end{array}$ & $\begin{array}{c}4.28 \pm \\
2.83\end{array}$ & $\begin{array}{c}-0.69 \pm \\
3.48\end{array}$ & -1.40 & 0.168 \\
\hline $\mathrm{TMH}$ & $\begin{array}{c}0.34 \pm \\
0.06\end{array}$ & $\begin{array}{c}0.33 \pm \\
0.06\end{array}$ & $\begin{array}{c}0.01 \pm \\
0.05\end{array}$ & 1.63 & 0.11 & $\begin{array}{c}0.37 \pm \\
0.08\end{array}$ & $\begin{array}{c}0.35 \pm \\
0.08\end{array}$ & $\begin{array}{c}0.02 \pm \\
0.08\end{array}$ & 1.91 & 0.062 & $\begin{array}{c}0.35 \pm \\
0.07\end{array}$ & $\begin{array}{c}0.34 \pm \\
0.08\end{array}$ & $\begin{array}{c}0.01 \pm \\
0.08\end{array}$ & 1.23 & 0.227 \\
\hline NITBUT & $\begin{array}{c}7.97 \pm \\
1.38\end{array}$ & $\begin{array}{c}6.06 \pm \\
0.89\end{array}$ & $\begin{array}{c}1.91 \pm \\
1.38\end{array}$ & 9.77 & $<0.001$ & $\begin{array}{c}6.76 \pm \\
1.12\end{array}$ & $\begin{array}{l}4.5 \pm \\
1.23\end{array}$ & $\begin{array}{c}2.26 \pm \\
1.49\end{array}$ & 7.94 & $<0.001$ & $\begin{array}{c}7.23 \pm \\
1.31\end{array}$ & $\begin{array}{c}5.84 \pm \\
1.34\end{array}$ & $\begin{array}{c}1.38 \pm \\
1.43\end{array}$ & 6.87 & $<0.001$ \\
\hline $\mathrm{SCH} 1$ & & & & & & $\begin{array}{c}17.46 \pm \\
6.58\end{array}$ & $\begin{array}{c}14.7 \pm \\
6.8\end{array}$ & $2.76 \pm$ & 5.4 & $<0.001$ & & & & & \\
\hline $\mathrm{SCH} 2$ & & & & & & & & & & & $\begin{array}{c}11.5 \pm \\
6.23\end{array}$ & $\begin{array}{c}7.54 \pm \\
5.6\end{array}$ & $\begin{array}{c}3.96 \pm \\
3.69\end{array}$ & 7.58 & $<0.001$ \\
\hline
\end{tabular}

Table a: Result.

There was a significant reduction in blink rate during jaw movement in all three conditions with $24.1 \pm 10.33,31.72 \pm 13.9,24.0 \pm 12.97$ respectively in without jaw movement to $17.5 \pm 8.34,25.72 \pm 13.28,18.46 \pm 11.12$ respectively during jaw movement.
There was a significant increase in inter blink interval values during jaw movement in all three conditions from $3.02 \pm 1.33 \mathrm{sec}, 2.3 \pm 1.21$ $\mathrm{sec}, 3.59 \pm 2.93 \mathrm{sec}$ respectively in without jaw movement to $4.32 \pm 2.52$ sec, $3.04 \pm 1.68 \mathrm{sec}, 3.59 \pm 2.93 \mathrm{sec}$ respectively during jaw movement. 
There was a significant reduction in non-invasive tear break up time during jaw movement in all three conditions from $7.97 \pm$ $1.38 \mathrm{sec}, 6.76 \pm 1.12 \mathrm{sec}, 7.23 \pm 1.31 \mathrm{sec}$ respectively in without jaw movement to $6.06 \pm 0.89 \mathrm{sec}, 4.5 \pm 1.23 \mathrm{sec}, 5.84 \pm 1.34 \mathrm{sec}$ respectively during jaw movement.

There was no significant reduction in tear meniscus height during jaw movement in all three conditions with $0.34 \pm 0.06 \mathrm{~mm}, 0.37$ $\pm 0.08 \mathrm{~mm}, 0.35 \pm 0.07 \mathrm{~mm}$ respectively in without jaw movement to $0.33 \pm 0.06 \mathrm{~mm}, 0.35 \pm 0.08 \mathrm{~mm}, 0.34 \pm 0.08 \mathrm{~mm}$ respectively in during jaw movement [1-10].

\section{BASAL BR}

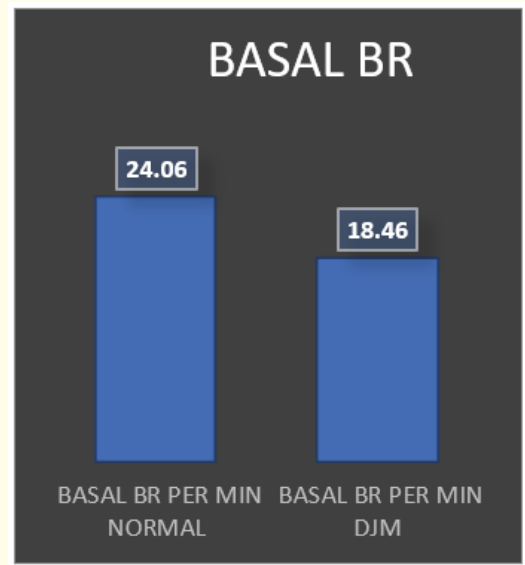

Graph 1

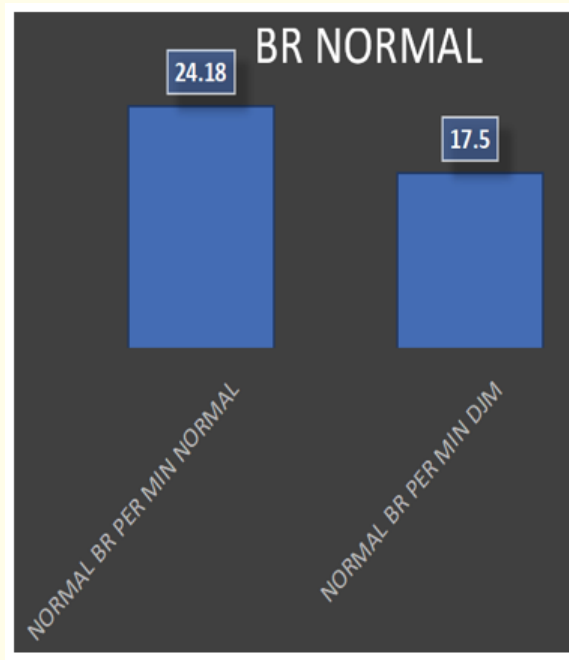

Graph 2

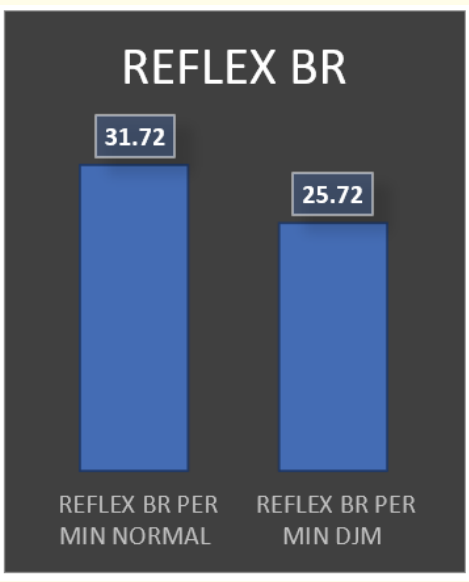

Graph 3

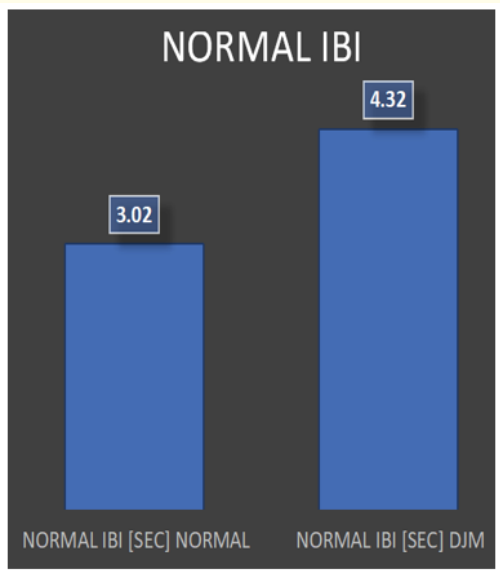

Graph 4

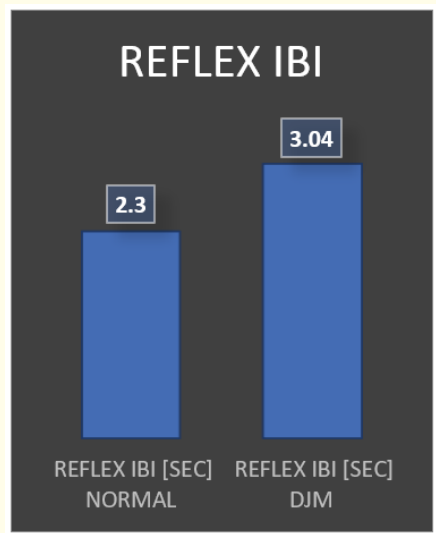

Graph 5 


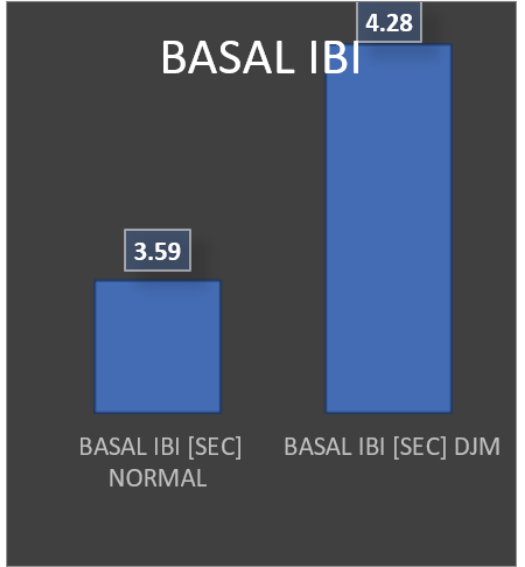

Graph 6

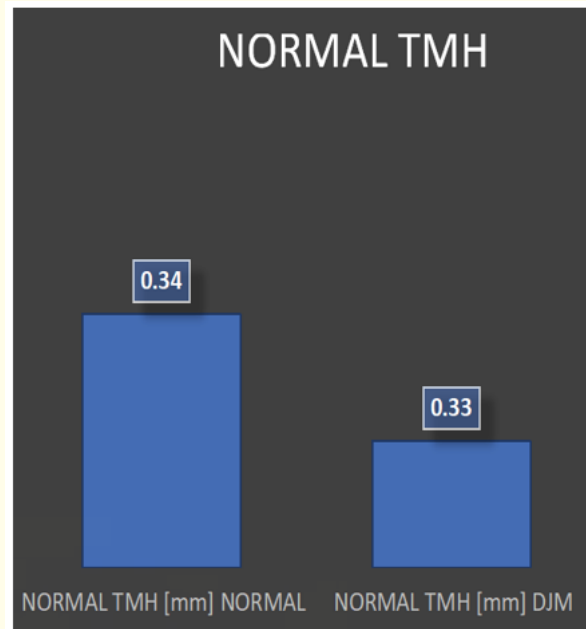

Graph 7

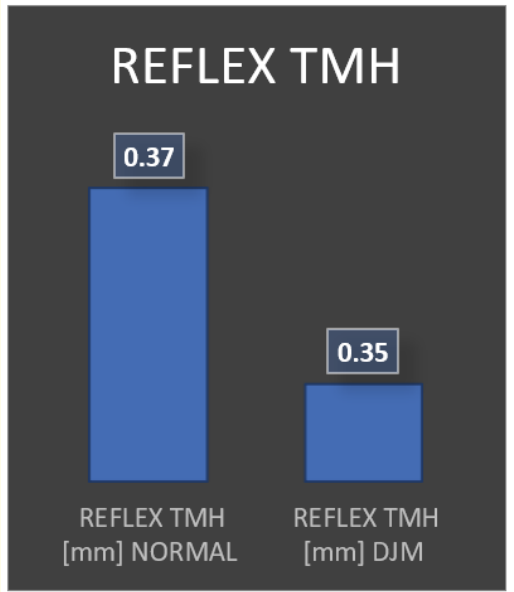

Graph 8

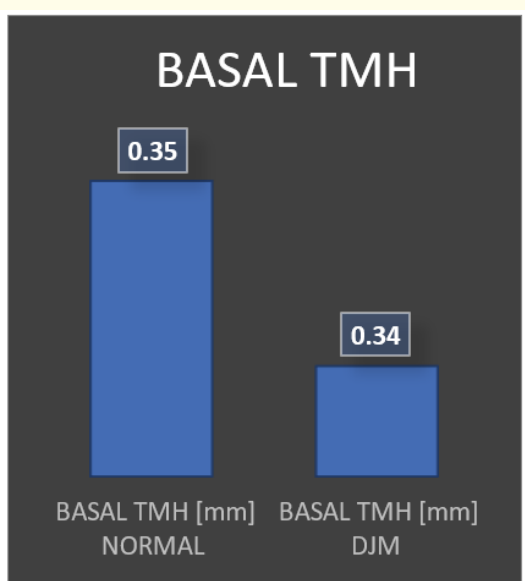

Graph 9

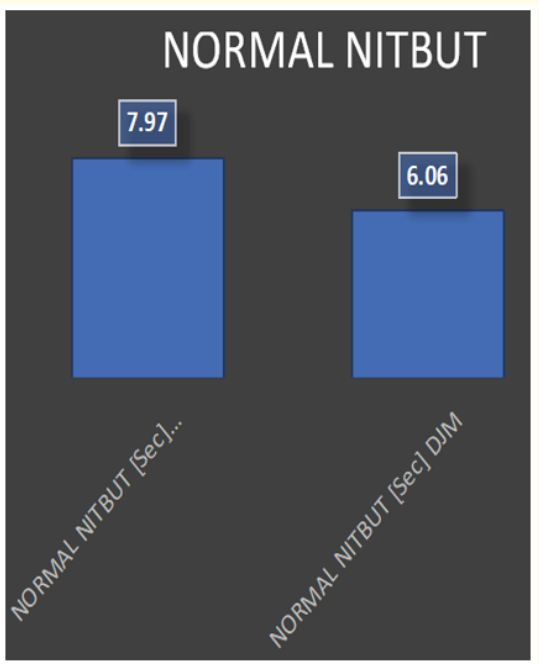

Graph 10

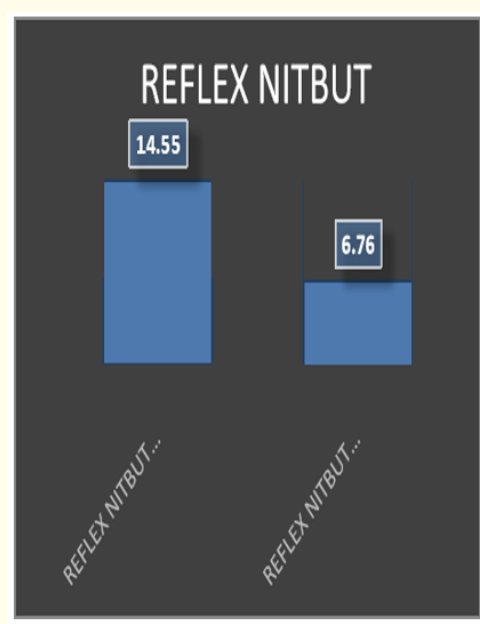

Graph 11 


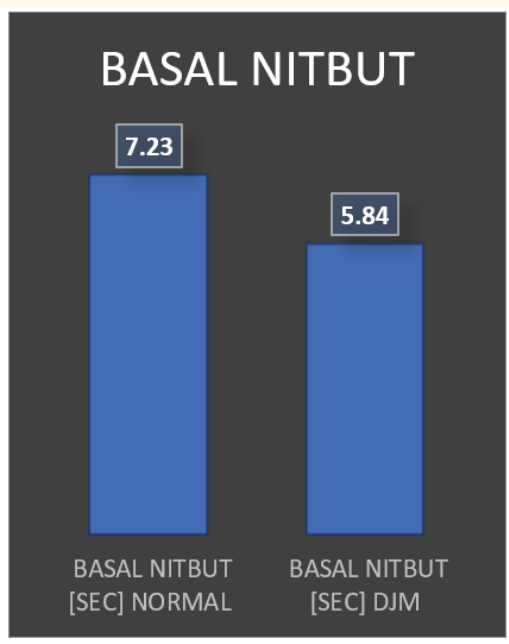

Graph 12

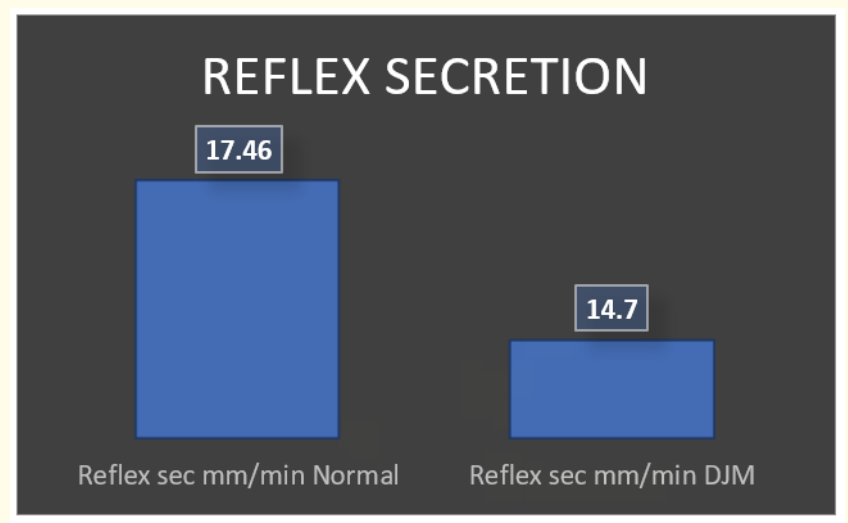

Graph 13

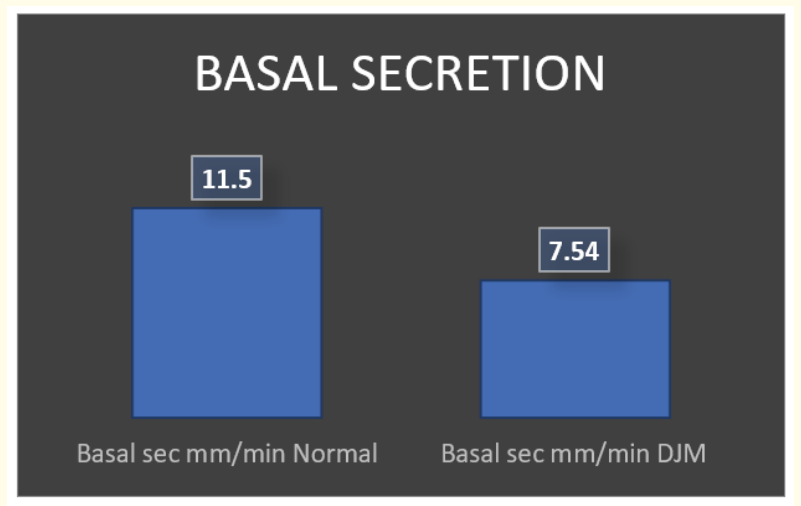

Graph 14

\section{Discussion}

- Mouth and jaw movements at a non-relaxed state can substantially increase spontaneous eye blinking. [Michael J Doughty Ph.D. First].

- In average SEBR values 13.5 blinks/minute,

- In relaxed state 13.9 and $12.0 \mathrm{blink} / \mathrm{min}$,

- In a non-relaxed state [spontaneous mouth and jaw movement] SEBR values around 27 blinks/min,

- In the mouth, open posture average SEBR was 7.2 blinks/min

- While engaged in causal conversation average SEBR of 20.3 blinks/min

- $\quad$ Chewing gum helps improve the ability of the eye to focus, especially in young adults [Asakawa K, Kanno S, Ando T, Osawa $\mathrm{K}$, Ishikawa $\mathrm{H}$ ]

- Topical ocular anesthesia reduces the rate of spontaneous blinking but does not change the distribution of inter-blink time intervals. [Borges FP, Garcia DM, Cruz AA]

- $\quad$ But in this study blink rate decreases during jaw movement compared to the base value in normal, reflex, and basal conditions.

\section{Conclusion}

With all the comparison of three stages

- There was a statistically significant reduction in blink rate during jaw movement and increased IBI value

- There was a statistically significant reduction of tear stability (NITBUT) during jaw movement

- There was a statistically significant reduction of tear secretion during jaw movement in reflex and basal condition

- There were no statistically significant changes in TMH.

\section{Limitation}

- We calculated blink rate for 1 minute, for further studies it is suggested to calculate blink rate for 5 minutes.

- In further studies, it would be advisable to include refractive error and contact lens.

\section{Bibliography}

1. Michael J Doughty. "Influence of mouth and jaw movements on dynamics of spontaneous eyeblink activity assessed during slit-lamp biomicroscopy". Clinical and Experimental Optometry 101.3 (2018). 
2. Michael J. "Effect of distance vision and refractive error on the spontaneous eyeblink activity in human subjects in primary eye gaze". Journal of Optometry 12.2 (2018).

3. Ping Situ and Trafford L Simpson. "Interaction of Corneal Nociceptive Stimulation and Lacrimal Secretion". Investigative Ophthalmology and Visual Science 51 (2010): 5640-5645.

4. Felipe Placeres Borges., et al. "Distribution of spontaneous inter-blink interval in repeated measurements with and without topical ocular anesthesia". Arquivos Brasileiros de Oftalmologia 73.4 (2010): 329-332.

5. Himebaugh, Nikole L., et al. "Blinking and Tear Break-Up During Four Visual Tasks". Optometry and Vision Science 86.2 (2009): E106-E114.

6. Anna Rita Bentivoglio., et al. "Analysis of blink rate patterns in normal subjects". Movement Disorder 12.6 (1997): 1028-1034.

7. Doughty MJ. “Consideration of three types of spontaneous eyeblink activity in normal humans: during reading and video display terminal use, in primary gaze, and while in conversation". Optometry and Vision Science 78.10 (2001): 712-725.

8. Cardona G, et al. "Blink rate, blink amplitude, and tear film integrity during dynamic visual display terminal tasks". Current Eye Research 36.3 (2011): 190-197.

9. York M., et al. "Variation in blink rate associated with contact lens wear and task difficulty". American Journal of Optometry and Archives of American Academy of Optometry 48 (1971): 461-467.

10. Tania Mara Schaefer., et al. "Comparative study of the blinking time between young adult and adult video display terminal users in the indoor environment". Arquivos Brasileiros de Oftalmologia 72.5 (2009): 682-686.

\section{Assets from publication with us}

- Prompt Acknowledgement after receiving the article

- Thorough Double blinded peer review

- Rapid Publication

- Issue of Publication Certificate

- High visibility of your Published work

Website: www.actascientific.com/

Submit Article: www.actascientific.com/submission.php

Email us: editor@actascientific.com

Contact us: +919182824667

Citation: Hari R., et al. "Effect of Jaw Movement in Blink Rate and Tear Volume". Acta Scientific Ophthalmology 5.2 (2022): 32-40. 